\title{
Editorial: premieres
}



Jean-Phillipe Fuzier

Editor-in-Chief

The city of Osaka in Japan will see the first fib congress in October this year. This will be quite an event. The congress is being organised by two hosts, the Japanese Concrete Institute and the Japanese Prestressed Concrete Engineering Association. The theme is 'Concrete Structures in the 21st century' and it intends to cover the prospect of concrete technology in this century, from the year
2001-2100. More than 800 abstracts have been received for contributions. Presentations and keynote lectures are scheduled over 15 different technical sessions. Nobody should miss this event!

This first 2002 issue of our journal is appearing in colour. As we are entering our third year of existence an effort is being made to be more attractive and seductive. I personally hope that we will attract both more authors and readers and that this will benefit our association and the success of the journal.

Finally, this is the first editorial of Structural Concrete, I am undertaking.
Andrew Beeby has had to give up being editor-in-chief of Structural Concrete for personal reasons and I have taken over from him. I would like to thank Andrew for everything he has done. As editor there is no more difficult task than to launch a magazine. This is what he has achieved during the past three years. The whole Editorial Board would like to express here its recognition to Andrew Beeby and is looking forward to receiving his continued support and active participation. 